\title{
The influence of extraction methods on composition and antioxidant properties of rice bran oil
}

\author{
Noppawat PENGKUMSRI ${ }^{1}$, Chaiyavat CHAIYASUT ${ }^{1}$, Bhagavathi Sundaram SIVAMARUTHI ${ }^{1}$, \\ Chalermpong SAENJUM ${ }^{1}$, Sasithorn SIRILUN ${ }^{1}$, Sartjin PEERAJAN², Prasit SUWANNALERT ${ }^{3}$, \\ Sophon SIRISATTHA ${ }^{4}$, Khontaros CHAIYASUT ${ }^{5}$, Periyanaina KESIKA ${ }^{1 *}$
}

\begin{abstract}
The current study was employed to assess the influence of the different extraction methods on total tocols, $\gamma$-oryzanol content, and antioxidant properties of Chiang Mai Black rice, Mali Red rice, and Suphanburi-1 Brown rice bran oil. Rice bran oil (RBO) was extracted by Hexane, Hot pressed, Cold pressed, and Supercritical Fluid Extraction (SFe) methods. High yield of RBO was extracted by hexane and SFe methods. Total and subgroups of tocols, and $\gamma$-oryzanol content were determined by HPLC. The hexane extracted sample accounts for high content of $\gamma$-oryzanol and tocols. Besides, all of RBO extracts contain a significantly high amount of $\gamma$-tocotrienol. In vitro antioxidant assay results indicated that superior quality of oil was recovered by hexane extraction. The temperature in the extraction process also affects the value of the oil. Superior quality of oil was recovered by hexane extraction, in terms of phytochemical contents and antioxidant properties compared to other tested extraction methods. Further, thorough study of factors compromising the quality and quantity of RBO recovery is required for the development of enhanced functional foods and other related products.
\end{abstract}

Keywords: rice bran oil; tocols; $\gamma$-oryzanol; antioxidants.

Practical Application: Influence of different extraction methods for the recovery of the principal compounds from RBO has been demonstrated.

\section{Introduction}

The seed of Oryza species is commonly known as rice, which are the foremost cereal food crop in most of the developing countries. Approximately $95 \%$ of the rice production is documented in Asian countries, and about half of the world population consumes rice as their primary source of carbohydrate (Muthayya et al., 2014). Rice grains, known as endosperm, are surrounded by nutrient rich (almost $60 \%$ of total nutritional value) outer layer called rice bran (RB) and it accounts for $8 \%$ of total weight of the rice. The color of the rice coat differs with respect to the degree of deposition of anthocyanin pigment. Consequently, the rice cultivars also varied with respect to the color of the rice, which can be black, brown, or red (Chaudhary, 2003).

Oryza sativa L. indica, commonly known as black rice (BIR), is routinely cultivated in Southeast Asian countries. BlR is reported to have an abundant amount of protein, vitamins, minerals and bioactive compounds with slight quantity variations which depends on land cultivation and diversity (Suzuki et al., 2004). $\mathrm{BlR}$ has been reported as one of the potential sources of antioxidants and health promoting compounds (Hu et al., 2003; Yawadio et al., 2007; Fardet et al., 2008; Goufo \& Trindade, 2014; Pengkumsri et al., 2015). BlR has the ability to prevent and can be useful to treat oxidative stress related diseases and cancer (Salgado et al., 2010). The outer layer of BlR is enriched with phytochemicals and these bioactive were broadly divided into polar (phenolic acids, flavonoids, anthocyanins) and non-polar components (tocopherols, tocotrienols, $\gamma$-oryzanol, and sterols) (Patel \& Naik. 2004; Zhou et al., 2004; Holtekjølen, et al., 2006). Studies have proven that the active components of RB improve the human health because of the high content of antioxidants (Laokuldilok et al., 2011). Jun et al. (2012) reported that black and red rice brans exhibited high content of phenolic compounds and antioxidant activity.

Rice bran oil (RBO) is one of the best sources of tocols and oryzanol. Tocols (tocopherols and tocotrienols), a family of vitamin E-active substances, are wildly used plant-based ingredients in the food, cosmetics and pharmaceutical industries (Bramley et al., 2000; Abidi, 2003). Studies suggested that tocotrienols are more efficient antioxidant, anti-cancer agent and inhibitor of cholesterol synthesis than the tocopherols (Singh et al., 2013). Gamma-oryzanol is one of the major components of RBO, and it is a mixture of several ferulate esters of triterpene alcohols and plant sterols (Friedman, 2013). Oryzanol is a well known

${ }^{1}$ Department of Pharmaceutical Sciences, Faculty of Pharmacy, Chiang Mai University - CMU, Chiang Mai, Thailand

${ }^{2}$ Health Innovation Institute, Chiang Mai, Thailand

${ }^{3}$ Department of Pathobiology, Faculty of Science, Mahidol University, Bangkok, Thailand

${ }^{4}$ Thailand Institute of Scientific and Technological Research - TISTR, Pathum Thani, Thailand

${ }^{5}$ Faculty of Education, Chiang Mai University - CMU, Chiang Mai, Thailand

*Corresponding author: p.kesika@gmail.com 
antioxidant compound and is linked with decreasing serum and plasma cholesterol, decreasing platelet aggregation, and cholesterol absorption. Moreover oryzanol has been used in the treatment of hyperlipidemia, and disorders of menopause (Patel \& Naik, 2004). The extraction and refining of RBO and the content of $\gamma$-oryzanol, along with its health benefits have been reviewed in detail (Patel \& Naik, 2004; Lerma-García et al., 2009). The quality and concentration of the tocols and $\gamma$-oryzanol content depend on the extraction processes and refining steps. Therefore, the current study was conceived to compare the non-polar extracts of CBIR, SBrR and MRR bran oil of Thai rice variety with respect to its tocols content, oryzanol content as well as its antioxidant properties.

\section{Materials and methods}

\subsection{Collection of rice bran and extraction}

Chiang Mai black rice (CBIR), Suphanburi-1 brown rice $(\mathrm{SBrR})$ and Mali red rice (MRR) were collected from the farm at Maerim district, Chiang Mai, Thailand and dried at $60^{\circ} \mathrm{C}$ for $48 \mathrm{~h}$. Then it was milled and the rice bran was separated through 60 -mesh strainer. Lipase in RB was destroyed through $100^{\circ} \mathrm{C}$ for 5 min thereafter $\mathrm{RB}$ was then stored at $-20^{\circ} \mathrm{C}$ until the time of processing. $\mathrm{RBO}$ was extracted with hexane (1:10 ratios of $\mathrm{RB}$ and hexane was incubated at $40^{\circ} \mathrm{C}$ with shaking at $150 \mathrm{rpm}$ for $30 \mathrm{~min}$ and thereafter filtrated through $0.45 \mu \mathrm{m}$ membrane and the solvent was evaporated to obtain crude RBO), hot press (screw pressing at $80-100^{\circ} \mathrm{C}$ ), cold press (screw pressing at $40-60^{\circ} \mathrm{C}$ ), and supercritical fluid $\left(40^{\circ} \mathrm{C}, 200 \mathrm{bar}, \mathrm{CO}_{2}\right.$ rate $15 \mathrm{~g} / \mathrm{min}, 1 \mathrm{~h}$ ) extraction. The collected oil samples were membrane filtered $(0.45 \mu \mathrm{m})$ and the percentage of yield was calculated (Equation 1).

Percentage of Yield $=(\mathrm{RBO}(\mathrm{g}) /$ Initial weight of RB $(\mathrm{g})) \times 100$

Filtered RBOs were stored at $-20^{\circ} \mathrm{C}$ under nitrogen gas $\left(\mathrm{N}_{2}\right)$ to prevent the degradation of active compounds until analysis.

\subsection{Determination of $\gamma$-oryzanol content}

$\gamma$-oryzanol content of RBO samples were determined by reversed-phase HPLC (Ajilent 1100, USA) (Chalermpong et al., 2012). The $\mathrm{ACE}^{\otimes} \mathrm{C} 18$ column $(250 \mathrm{~mm} \times 4.6 \mathrm{~mm} ; 5 \mu \mathrm{m})$ was used. Solvent mixture of methanol (50\%), acetonitrile (44\%), acetic acid (3\%), and dichloromethane (3\%) was used as mobile phase under isocratic condition. UV detector at $330 \mathrm{~nm}$ was equipped for the sample detection, and the flow rate was set at $1 \mathrm{~mL} / \mathrm{min}$. All the samples were measured in triplicate.

\subsection{Determination of tocols content}

The tocols content (both tocotrienols and tocopherols) of RBO samples were evaluated by reversed-phase HPLC which is equipped with LC-10AV VP pumps, SPD-10AV VP (Shimadzu, Japan) and fluorescent detector (Bruscatto et al., 2009). The KINETEX PFP column $(150 \mathrm{~mm} \times 4.6 \mathrm{~mm} ; 100 \mathrm{~A})$, was used (Phenomenex, USA) and 90\% methanol in deionized water acts as mobile phase. The flow rate was set at $0.5 \mathrm{~mL} / \mathrm{min}$. The excitation and emission wavelength was set at 296 and $325 \mathrm{~nm}$, respectively. All the samples were measured in triplicate.

\subsection{Determination of antioxidant capacity}

Antioxidant capacity of RBO extracts were assessed by ABTS (2, 2'-azino-bis-3-ethylbenzthiazoline-6-sulphonic acid), DPPH (1, 1-diphenyl-2-picryl-hydrazil), FRAP (Ferric reducing antioxidant power), Nitric oxide ( $\left.\mathrm{NO}^{\circ}\right)$, Superoxide $\left(\mathrm{O}_{2}{ }^{-}\right)$radical scavenging assay and inhibition of lipid peroxidation (LPO) assay as described in our previous publications. $\mathrm{ABTS}^{-+}$radical scavenging activity was measured by ABTS assay according to Chalermpong et al. (2012). DPPH• radical scavenging activity was assessed by DPPH assay according to Rattanachitthawat et al. (2010) and Wahid et al. (2014). FRAP assay was performed according to the method of Suwannalert et al. (2010) and inhibition of lipid peroxidation was assessed according to Chalermpong et al. (2012). Nitric oxide (NO*) radical scavenging activity was measured according to Francis \& Andrew (2010) and Pengkumsri et al. (2015). Superoxide $\left(\mathrm{O}_{2}^{*}\right)$ radical scavenging activity was assessed according to Kusirisin et al. (2009).

\subsection{Statistical analysis}

The quantification of $\gamma$-oryzanol, tocols (tocotrienols and tocopherols) content and determination of antioxidant activity of $\mathrm{RBO}$ were performed in triplicates to confirm the reproducibility of the results. The report of the data was given as mean \pm SD. Analysis of variance (ANOVA) was performed using statistical SPSS software version 17 (Chicago, SPSS Inc, U.S.A). The Least Significant Difference (LSD) post hoc test was performed in order to analyze the significant differences in antioxidant activities and $p<0.05$ was considered to be significant.

\section{Results and discussion}

The yield of RBO during different extraction methods has been tabulated (Table 1). The hexane extraction $(\mathrm{He})$ of CBlR, $\mathrm{MRR}$, and SBrR yielded about $11.61 \pm 0.55,10.92 \pm 0.64$, and $12.89 \pm 0.58 \%$ of $\mathrm{RBO}$, respectively. The supercritical fluid extraction (SFe) of CBIR, MRR, and SBrR yielded about $9.60 \pm 1.06$, $8.12 \pm 0.97$, and $7.06 \pm 0.78 \%$ of $\mathrm{RBO}$, respectively. The yield of RBO suggested that hexane extraction (He) produced high quantity of oil followed by SFe (Table 1).

The $\gamma$-oryzanol content of RBO has been assessed by HPLC with respect to different extraction methods. About $17.54 \pm 0.75$, $17.54 \pm 0.88$, and $18.49 \pm 1.52 \mathrm{mg} / \mathrm{g}$ of $\gamma$-oryzanol content in CBIR, MRR, and SBrR bran oil, respectively were recorded in hexane extracts, whereas a very low amount $(1.75 \pm 0.09$ and $2.71 \pm 0.14 \mathrm{mg} / \mathrm{g}$ in CBlR and SBrR, respectively) of $\gamma$-oryzanol were observed in RBO obtained by SFe. Hot press extraction yielded $5.62 \pm 0.28,5.66 \pm 0.25$, and $6.23 \pm 0.31 \mathrm{mg} / \mathrm{g}$ of $\gamma$-oryzanol content in CBIR, MRR, and SBrR bran oil extract, respectively. Cold press extraction represented $6.08 \pm 0.34,6.75 \pm 0.3$, and $6.48 \pm 0.37 \mathrm{mg} / \mathrm{g}$ of $\gamma$-oryzanol content in CBIR, MRR, and SBrR bran oil, respectively (Figure 1). Previous studies have been reported on the recovery of $\gamma$-oryzanol from different $R B$ varieties by methanol, hexane, and ethyl acetate mediated extraction techniques (Iqbal et al., 2005; Chotimarkorn et al., 2008; Lin \& Lai, 2011). Varying quantity of $\gamma$-oryzanol have been reported based on the extraction methods and rice cultivars. In the present study, highest $\gamma$-oryzanol yield was obtained by He followed by 
Pengkumsri et al.

Table 1. Recovery of Rice bran oil from different rice cultivars with different extraction methods and sample codes used in the current study.

\begin{tabular}{cccc}
\hline Extraction method & Sample & Sample code & \% of yield \\
\hline Hexane extraction (He) & Chiang Mai Black rice (CBlR) & He-CBlR & $11.61 \pm 0.55^{\star}$ \\
& Mali Red rice (MRR) & He-MRR & $10.92 \pm 0.64^{*}$ \\
& Suphanburi Brown rice (SBrR) & He-SBrR & $12.89 \pm 0.58^{*}$ \\
Hot press extraction (HPe) & Chiang Mai Black rice (CBlR) & HPe-CBlR & $5.81 \pm 0.87$ \\
& Mali Red rice (MRR) & HPe-MRR & $7.01 \pm 1.05$ \\
& Suphanburi Brown rice (SBrR) & HPe-SBrR & $5.59 \pm 0.84$ \\
Cold press extraction (CPe) & Chiang Mai Black rice (CBlR) & CPe-CBlR & $4.04 \pm 0.81$ \\
& Mali Red rice (MRR) & CPe-MRR & $5.80 \pm 1.16$ \\
Supercritical fluid extraction (SFe) & Chiang Mai Black rice (CBlR) & CPe-SBrR & $4.85 \pm 0.97$ \\
& Saphe-CBlR & $9.60 \pm 1.06$ \\
& Suphanburi Brown rice (SBrR) & SFe-MRR & $8.12 \pm 0.97$ \\
\end{tabular}

*\% of yield is significant $(p<0.05)$ compared to respective RBO extract of other extraction methods (HPe, CPe and SFe).

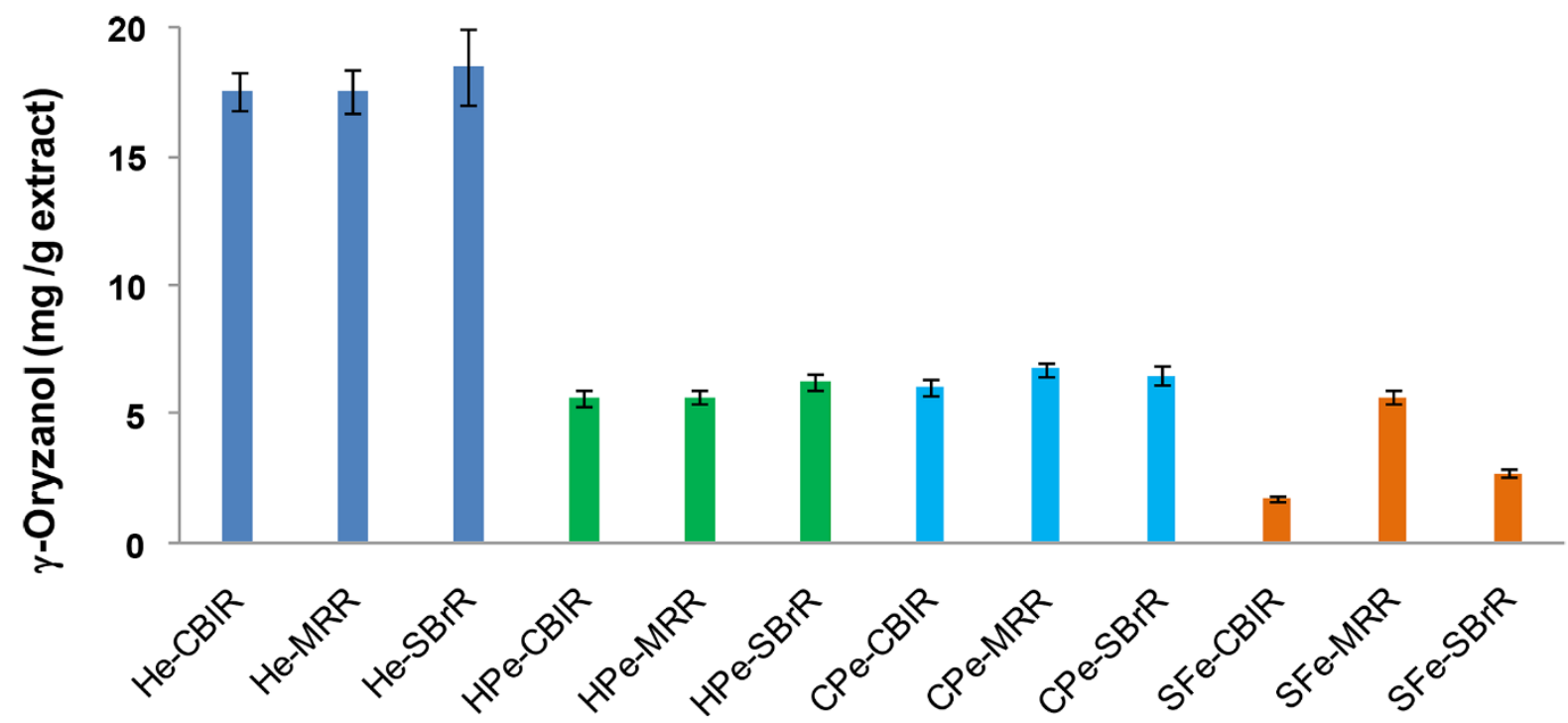

Figure 1. $\gamma$-oryzanol content in $\mathrm{CBlR}, \mathrm{SBrR}$, and MRR bran oil extracted by $\mathrm{He}, \mathrm{HPe}, \mathrm{CPe}$, and $\mathrm{SFe}$. The values were represented as mean $\pm \mathrm{SD}$.

$\mathrm{CPe}, \mathrm{HPe}$ and SFe methods (Figure 1). This data suggested that variation in the amount of $\gamma$-oryzanol in RBO depends on the extraction methods.

Total tocols and subgroups of tocopherol and tocotrienol were measured. The total tocopherol (included $\alpha, \beta, \gamma$, and $\delta$ ) content of about $0.40 \pm 0.02,0.15 \pm 0.01,0.16 \pm 0.01$, and $0.08 \pm 0.00 \mathrm{mg} / \mathrm{g}$ in $\mathrm{CBlR}$ bran oil samples were obtained from $\mathrm{He}, \mathrm{HPe}, \mathrm{CPe}$, and $\mathrm{SFe}$ methods, respectively. The total tocopherol content of about $0.22 \pm 0.01,0.19 \pm 0.01,0.21 \pm 0.01$, and $0.05 \pm 0.00 \mathrm{mg} / \mathrm{g}$ in MRR bran oil samples were obtained from $\mathrm{He}, \mathrm{HPe}, \mathrm{CPe}$, and $\mathrm{SFe}$ methods, respectively. The total tocopherol content of about $0.43 \pm 0.02,0.12 \pm 0.01,0.13 \pm 0.01$, and $0.06 \pm 0.00 \mathrm{mg} / \mathrm{g}$ in SBrR bran oil samples were obtained from $\mathrm{He}, \mathrm{HPe}, \mathrm{CPe}$, and $\mathrm{SFe}$ methods, respectively. In all the preparations, $\gamma$-tocopherol was found to be a major subgroup of tocopherol followed by $\alpha, \delta$ and $\beta$ types that were recorded for their abundance, respectively. The total tocopherol concentration also suggested that hexane extraction is significantly $(p<0.05)$ better than the other mining methods employed in the present study. The total tocotrienol (included $\alpha, \beta, \gamma$, and $\delta$ ) content of about $0.67 \pm 0.03,0.28 \pm 0.01,0.34 \pm 0.02$, and $0.18 \pm 0.01 \mathrm{mg} / \mathrm{g}$ in CBlR bran oil samples were obtained from $\mathrm{He}, \mathrm{HPe}, \mathrm{CPe}$, and SFe methods, respectively. The total tocotrienol content of about $0.84 \pm 0.04,0.62 \pm 0.03,0.74 \pm 0.04$, and $0.26 \pm 0.01 \mathrm{mg} / \mathrm{g}$ in MRR bran oil were obtained from $\mathrm{He}, \mathrm{HPe}, \mathrm{CPe}$, and SFe methods, respectively. The total tocotrienol content of about $1.11 \pm 0.06$, $0.52 \pm 0.03,0.62 \pm 0.03$, and $0.31 \pm 0.02 \mathrm{mg} / \mathrm{g}$ in SBrR bran oil samples were obtained from $\mathrm{He}, \mathrm{HPe}, \mathrm{CPe}$, and SFe methods, respectively. The quantification of sub-groups revealed that the abundance of $\gamma$ - tocotrienol was higher and followed by $\alpha$ - tocotrienol, $\delta$ - tocotrienol, and $\beta$ - tocotrienol (Figure 2). The quantity of $\delta$ and $\beta$ type of tocopherol and tocotrienol have no significant variation in both cold and hot press extraction. The quantity of $\delta$ and $\beta$ type tocopherol and tocotrienol were not significantly affected by the cold press and hot press extraction when compared to the yield of hexane extracts. Similar to tocopherol, the abundance of tocotrienol was also recorded in hexane extracted oil (Figure 2). Chotimarkorn et al. (2008) 

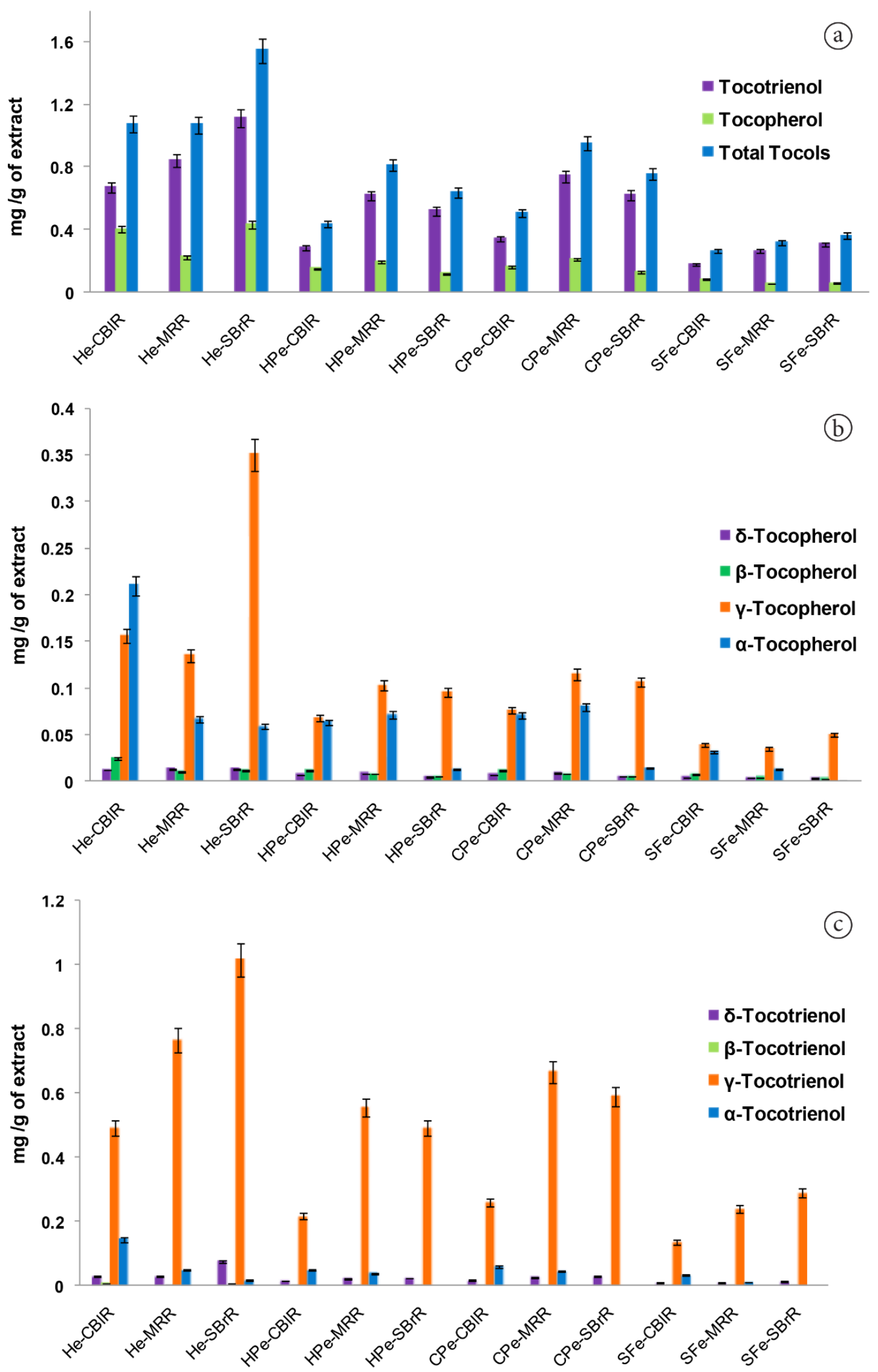

Figure 2. Total (a) and subgroups of tocopherol (b) and tocotrienol (c) content in CBIR, SBrR and MRR bran oil extracted by He, HPe, CPe, and $\mathrm{SFe}$. The values were represented as mean $\pm \mathrm{SD}$. 
has reported the richness of $\alpha$-tocopherol and the absence of $\gamma$-tocotrienol in the methanolic extraction of RB than in those of the other types. Basically, concentration of total tocopherol and tocotrienol content variation depends on the cultivars and the extraction method used. Moreover, few studies have reported that the extractions of all the subgroups of tocols are not entirely succeeded in an efficient manner (Iqbal et al., 2005; Aguilar-Garcia et al., 2007). In the present study, all subgroups of tocols were reported in all the preparations with varying concentration.

Anti-oxidant properties of RBO have been studied through different in vitro assays such as ABTS, DPPH, FRAP, Inhibition of lipid peroxidation, superoxide anion, and nitric oxide radical scavenging assay. Hexane extracted samples showed the highest TEAC (mg of trolox equivalent antioxidant capacity per gram of extracts) $(13.16 \pm 0.66,13.05 \pm 0.65$, and $17.17 \pm 0.86 \mathrm{mg}$ TEAC/g of CBlR, MRR, and SBrR bran oil extract, respectively) in ABTS assay compared to the samples extracted by HPe, $\mathrm{CPe}$, and SFe methods (Figure 3a). Hexane extracted SBrR bran oil showed the highest $\mathrm{ABTS}^{-+}$radical scavenging activity $\left(\mathrm{IC}_{50}=29.31 \pm 0.17 \mu \mathrm{g} / \mathrm{mL}\right)$ compared to the other samples (Table 2). DPPH assay also suggested that hexane extracted samples exhibit significant anti-oxidant activity $(12.42 \pm 0.58,12.19 \pm 0.56$, and $18.80 \pm 0.57 \mathrm{mg}$ TEAC/g of CBlR, MRR, and SBrR bran oil extract, respectively) compared to the samples extracted by other methods (Figure 3b). Similarly, hexane extracted SBrR bran oil showed the highest DPPH radical scavenging activity $\left(\mathrm{IC}_{50}=0.70 \pm 0.04 \mathrm{mg} / \mathrm{mL}\right.$ ) compared to other samples (Table 2). Inhibition of Lipid peroxidation assay results indicated that hexane extracted sample has the maximum inhibition activity $(27.76 \pm 0.25,27.51 \pm 0.23$, and $30.49 \pm 0.51 \mathrm{mg} \mathrm{TEAC} / \mathrm{g}$ (Figure $3 \mathrm{c})$; $\mathrm{IC}_{50}=0.67 \pm 0.03,0.67 \pm 0.03,0.61 \pm 0.03 \mathrm{mg} / \mathrm{mL}$ (Table 2) of CBlR, MRR, and SBrR bran oil extract, respectively) compared to the samples extracted by other methods. The reducing power of hexane extracted samples $(24.53 \pm 1.23,33.41 \pm 1.67$, and $35.03 \pm 1.75 \mathrm{mg}$ equivalent $\mathrm{FeSO}_{4}$ per gram of $\mathrm{CBlR}, \mathrm{MRR}$, and SBrR bran oil extract, respectively) were observed to be higher compared to the samples extracted by HPe, CPe, and
SFe methods (Figure 4). Superoxide $\left(\mathrm{O}_{2}^{-{ }^{-}}\right)$radical scavenging assay results showed that hexane extracted samples exhibited higher $\mathrm{O}_{2}^{--}$radical scavenging activity $(7.34 \pm 0.10,7.01 \pm 0.12$, and $7.00 \pm 0.12 \mu \mathrm{g}$ ascorbic acid equivalent/ $\mu \mathrm{g}$ (Figure 5a); $\mathrm{IC}_{50}=12.49 \pm 0.62,13.07 \pm 0.65,13.09 \pm 0.65 \mu \mathrm{g} / \mathrm{mL}$ (Table 2 ) of $\mathrm{CBlR}, \mathrm{MRR}$, and SBrR bran oil extract, respectively) compared to the samples extracted by $\mathrm{HPe}, \mathrm{CPe}$, and SFe methods. Nitric oxide (NO*) radical scavenging assay results also showed that hexane extracted samples exhibited higher $\mathrm{NO}^{*}$ radical scavenging activity $(0.23 \pm 0.01,0.23 \pm 0.01$, and $0.20 \pm 0.01 \mathrm{mg}$ curcumin equivalent $/ \mathrm{mg}$ (Figure 5b); $\mathrm{IC}_{50}=0.18 \pm 0.00,0.18 \pm 0.00$, $0.21 \pm 0.01 \mathrm{mg} / \mathrm{mL}$ (Table 2) of CBlR, MRR, and SBrR bran oil extract, respectively) compared to the samples extracted by $\mathrm{HPe}, \mathrm{CPe}$, and SFe methods.

Therefore, all in vitro antioxidant assay results indicated that He based RBO preparations are enriched with antioxidant properties significantly $(p<0.05)$ than other tested HPe, CPe, and SFe based RBO preparations. Even though, hexane extraction yields efficient and enriched $\mathrm{RBO}$, the presence of hexane residues that are not completely eliminated is the disadvantage of the solvent based extraction process. The present study also investigated the efficiency of RBO yielded by the solvent independent extraction process. Overall results indicated that the efficiency of $\mathrm{HPe}$, $\mathrm{CPe}$, and $\mathrm{SFe}$ which are solvent independent extraction process is less compared to the $\mathrm{He}$ of $\mathrm{RBO}$. The second high yield of RBO was obtained by SFe (Table 1), but the quality of the oil was slightly compromised in its antioxidant property compared to HPe and CPe samples (Figures 3 and 5). The oil extraction temperature greatly influenced the yield and quality of the oil. Hot pressed method produced a slightly enhanced yield of RBO compared to cold pressed, but the quality of cold pressed oil in terms of antioxidant properties was superior to the hot pressed one (Figures 3 and 5).

Considerable differences in antioxidant capacity of RBO extracts of different cultivars suggested that the content of the phytochemicals had a vast impact on their antioxidant properties (Iqbal et al., 2005; Chotimarkorn et al., 2008). The chemical composition (tocols, $\gamma$-oryzanol), and antioxidant

Table 2. Antioxidant activity $\left(\mathrm{IC}_{50}\right)$ of different Rice bran oil extracts with different evaluation method.

\begin{tabular}{|c|c|c|c|c|c|}
\hline $\begin{array}{l}\text { RB oil extract } \\
\text { sample code }\end{array}$ & $\begin{array}{c}\text { ABTS assay } \\
(\mu \mathrm{g} / \mathrm{mL})\end{array}$ & $\begin{array}{l}\text { DPPH assay } \\
(\mathrm{mg} / \mathrm{mL})\end{array}$ & $\begin{array}{c}\text { NO• radical } \\
\text { scavenging assay } \\
(\mu \mathrm{g} / \mathrm{mL})\end{array}$ & $\begin{array}{c}\mathrm{O}_{2} \cdot-\text { radical } \\
\text { scavenging assay } \\
(\mu \mathrm{g} / \mathrm{mL})\end{array}$ & $\begin{array}{c}\text { Inhibition of Lipid } \\
\text { Peroxidation } \\
(\mathrm{mg} / \mathrm{mL}) \\
\end{array}$ \\
\hline $\mathrm{He}-\mathrm{CBlR}$ & $37.32 \pm 0.28^{*}$ & $1.06 \pm 0.05^{\star}$ & $0.18 \pm 0.00^{*}$ & $12.49 \pm 0.62^{*}$ & $0.67 \pm 0.03^{*}$ \\
\hline He-MRR & $38.44 \pm 0.30^{*}$ & $1.08 \pm 0.05^{\star}$ & $0.18 \pm 0.00^{*}$ & $13.07 \pm 0.65^{\star}$ & $0.67 \pm 0.03$ \\
\hline $\mathrm{He}-\mathrm{SBrR}$ & $29.31 \pm 0.17^{\star}$ & $0.70 \pm 0.04^{\star}$ & $0.21 \pm 0.01^{\star}$ & $13.09 \pm 0.65^{\star}$ & $0.61 \pm 0.03^{\star}$ \\
\hline $\mathrm{HPe}-\mathrm{CBlR}$ & $96.83 \pm 0.22$ & $1.81 \pm 0.09$ & $0.29 \pm 0.01$ & $20.61 \pm 1.03$ & $1.07 \pm 0.05$ \\
\hline HPe-MRR & $84.07 \pm 0.25$ & $1.92 \pm 0.09$ & $0.31 \pm 0.01$ & $20.01 \pm 1.00$ & $0.72 \pm 0.04$ \\
\hline HPe-SBrR & $87.93 \pm 0.34$ & $2.22 \pm 0.10$ & $0.32 \pm 0.01$ & $21.33 \pm 1.06$ & $0.99 \pm 0.05$ \\
\hline CPe-CBlR & $68.92 \pm 0.32$ & $1.52 \pm 0.08$ & $0.24 \pm 0.01$ & $14.48 \pm 0.72$ & $0.82 \pm 0.04$ \\
\hline CPe-MRR & $76.50 \pm 0.16$ & $1.65 \pm 0.08$ & $0.23 \pm 0.01$ & $15.78 \pm 0.78$ & $0.70 \pm 0.04$ \\
\hline CPe-SBrR & $69.55 \pm 0.42$ & $1.64 \pm 0.08$ & $0.25 \pm 0.01$ & $16.90 \pm 0.85$ & $0.81 \pm 0.04$ \\
\hline SFe-CBlR & $170.01 \pm 0.33$ & $2.46 \pm 0.12$ & $0.29 \pm 0.01$ & $19.17 \pm 0.95$ & $1.48 \pm 0.07$ \\
\hline SFe-MRR & $129.67 \pm 0.43$ & $2.03 \pm 0.10$ & $0.29 \pm 0.01$ & $18.85 \pm 0.94$ & $1.41 \pm 0.07$ \\
\hline SFe-SBrR & $119.53 \pm 0.55$ & $1.90 \pm 0.09$ & $0.32 \pm 0.01$ & $19.54 \pm 0.97$ & $1.23 \pm 0.06$ \\
\hline
\end{tabular}

All the values are represented as mean \pm SD of triplicate experiments. ${ }^{*} \mathrm{IC}_{50}$ value is significant $(p<0.05)$ compared to respective $\mathrm{RB}$ oil extract of other extraction methods $(\mathrm{HPe}, \mathrm{CPe}$ and $\mathrm{SFe}$ ). 

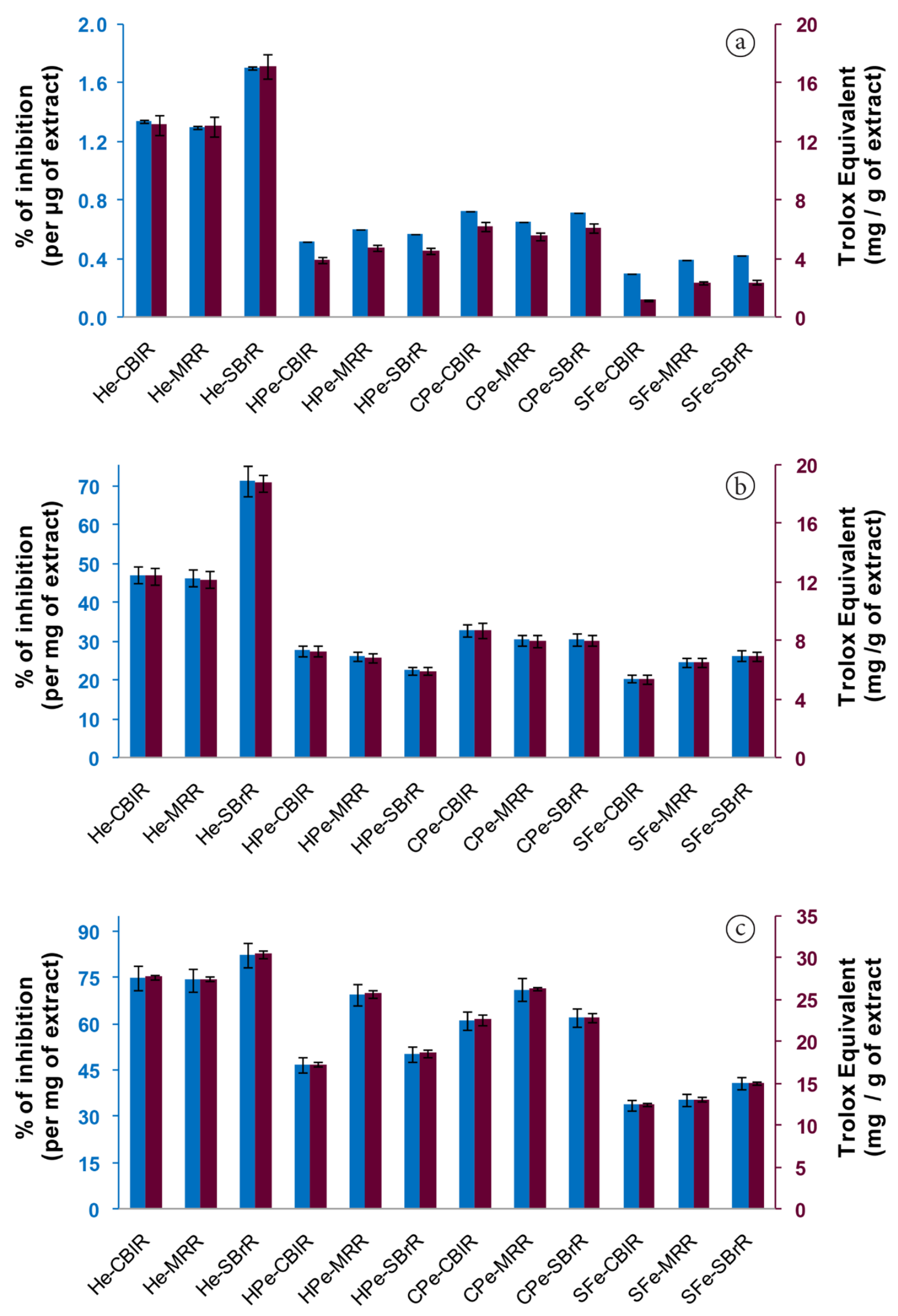

Figure 3. ABTS (a), DPPH (b) and Lipid peroxidation (c) inhibition activity of RBO extracts in comparison with its standard. The values were represented as mean $\pm \mathrm{SD}$. 


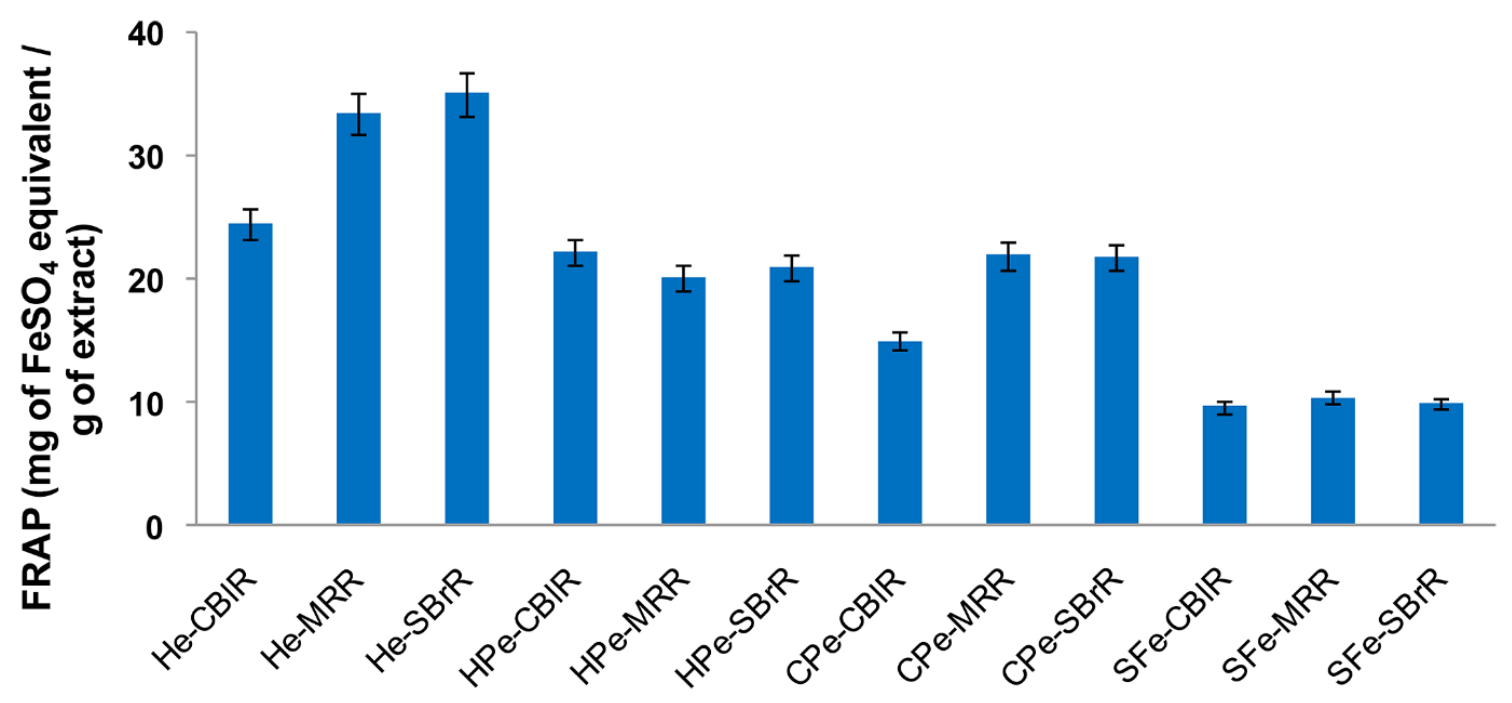

Figure 4. Reducing power of RBO extracts assessed by FRAP assay. The values were represented as mean \pm SD.
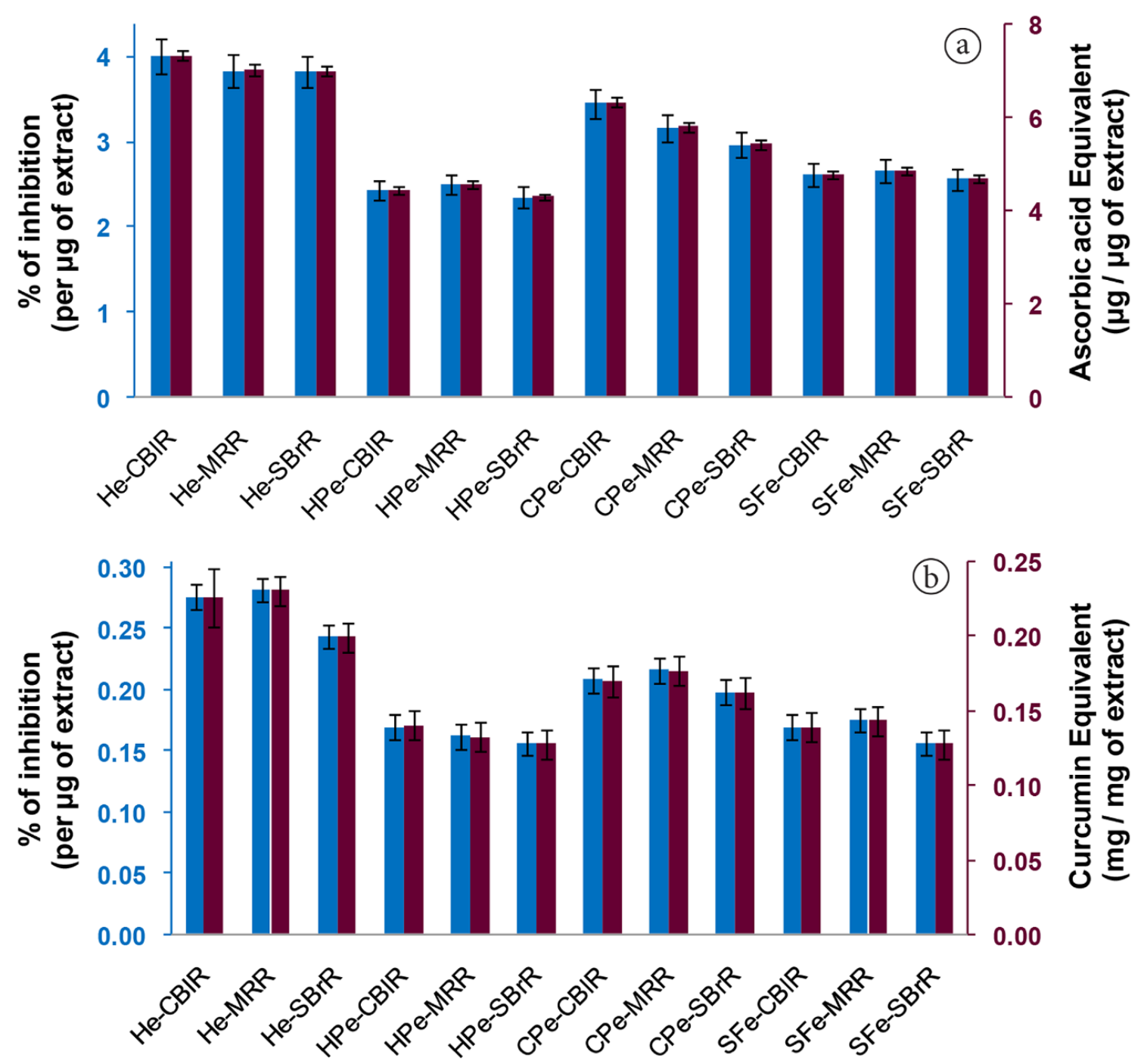

Figure 5. Superoxide $\left(\mathrm{O}_{2}^{*}\right)$ radical (a) and nitric oxide $(\mathrm{NO} \cdot)$ radical (b) scavenging activity of RBO extracts in comparison with its standard. The values were represented as mean $\pm \mathrm{SD}$. 
properties of white, red, and brown rice bran were compared with the unique extraction method (Aguilar-Garcia et al., 2007; Finocchiaro et al., 2007). However, all previous studies have shown that the phytochemical composition and the ability of the antioxidant of rice varieties depend on many factors, majorly, cultivars, and extraction methods. The results of the current investigation suggested that hexane extraction yielded prosperous $\mathrm{RBO}$ with respect to the content of active phytochemicals and antioxidants. Development of new or modified extraction method independent of solvent usage that provides an efficient yield of RBO will eliminate the health hazards that might occur when used in food, cosmetic and pharmaceutical industries.

\section{Conclusion}

The influence of the different extraction methods on the recovery of the principal compounds like total tocols and $\gamma$-oryzanol from RBO has been demonstrated. The effect of extraction methods on antioxidant activities of the same cultivar was also studied. This study revealed that hexane extraction yielded precious $\mathrm{RBO}$, with respect to both quantity and quality wise. The SFE affects the desired qualities of RBO though it gives better yield in terms of quantity. The role of the temperature in $\mathrm{RBO}$ recovery and property was also explained. To the best of our knowledge, this is the primary study about the influence of extraction methods on phytochemical content and antioxidant properties of CBIR, MRR, and SBrR bran oil. Further, in-depth study on factors affecting the recovery of phytonutrients and its properties is required for the development of enhanced functional foods and other related products.

\section{Acknowledgements}

This study was financially supported by Thailand Agricultural Research Development Agency (ARDA), and National Research Council of Thailand (NRCT), Thailand. PK also gratefully acknowledges the CMU Post-Doctoral Fellowship, the Faculty of Pharmacy and Chiang Mai University, Chiang Mai, Thailand.

\section{References}

Abidi, S. L. (2003). Tocol-derived minor constituents in selected plant seed oils. Journal of the American Oil Chemists' Society, 80(4), 327333. http://dx.doi.org/10.1007/s11746-003-0698-9.

Aguilar-Garcia, C., Gavino, G., Baragano-Mosqueda, M., Hevia, P., \& Gavino, V. C. (2007). Correlation of tocopherol, tocotrienol, $\gamma$-oryzanol and total polyphenol content in rice bran with different antioxidant capacity assays. Food Chemistry, 102(4), 1228-1232. http://dx.doi.org/10.1016/j.foodchem.2006.07.012.

Bramley, P. M., Elmadfa, I., Kafatos, A., Kelly, F. J., Manios, Y., Roxborough, H. E., Schuch, W., Sheehy, P. J. A., \& Wagner, K. H. (2000). Vitamin E. Journal of the Science of Food and Agriculture, 80(7), 913-938. http:// dx.doi.org/10.1002/(SICI)1097-0010(20000515)80:7<913::AIDJSFA600 $>3.0 . C O ; 2-3$.

Bruscatto, M. H., Zambiazi, R. C., Sganzerla, M., Pestana, V. R., Otero, D., Lima, R., \& Paiva, F. (2009). Degradation of tocopherols in rice bran oil submitted to heating at different temperatures. Journal of Chromatographic Science, 47(9), 762-765. http://dx.doi.org/10.1093/ chromsci/47.9.762. PMid:19835684.
Chalermpong, S., Chaiyavat, C., Sunee, C., Suttajit, M., \& Sirithunyalug, B. (2012). Antioxidant and anti-inflammatory activities of gammaoryzanol rich extracts from Thai purple rice bran. Journal of Medicinal Plants Research, 6(6), 1070-1077.

Chaudhary, R. C. (2003). Speciality rices of the world: Effect of WTO and IPR on its production trend and marketing. Food. Agriculture and Environment, 1(2), 34-41.

Chotimarkorn, C., Benjakul, S., \& Silalai, N. (2008). Antioxidant components and properties of five long-grained rice bran extracts from commercial available cultivars in Thailand. Food Chemistry, 111(3), 636-641. http://dx.doi.org/10.1016/j.foodchem.2008.04.031.

Fardet, A., Rock, E., \& Remesy, C. (2008). Is the in vitro antioxidant potential of whole-grain cereals and cereal products well reflected in vivo? Journal of Cereal Science, 48(2), 258-276. http://dx.doi. org/10.1016/j.jcs.2008.01.002.

Finocchiaro, F., Ferrari, B., Gianinetti, A., Dall'asta, C., Galaverna, G., Scazzina, F., \& Pellegrini, N. (2007). Characterization of antioxidant compounds of red and white rice and changes in total antioxidant capacity during processing. Molecular Nutrition \& Food Research, 51(8), 1006-1019. http://dx.doi.org/10.1002/mnfr.200700011. PMid:17639995.

Francis, M. A., \& Andrew, W. V. (2010). Antioxidant activity, nitric oxide scavenging activity and phenolic contents of Ocimum gratissimum leaf extract. Journal of Medicinal Plants Research, 4(23), 2479-2487.

Friedman, M. (2013). Rice brans, rice bran oils, and rice hulls: composition, food and industrial uses, and bioactivities in humans, animals, and cells. Journal of Agricultural and Food Chemistry, 61(45), 10626-10641. http://dx.doi.org/10.1021/jf403635v. PMid:24175575.

Goufo, P., \& Trindade, H. (2014). Rice antioxidants: phenolic acids, flavonoids, anthocyanins, proanthocyanidins, tocopherols, tocotrienols, $\gamma$-oryzanol, and phytic acid. Food Science \& Nutrition, 2(2), 75-104. http://dx.doi.org/10.1002/fsn3.86. PMid:24804068.

Holtekjølen, A. K., Uhlen, A. K., Bråthen, E., Sahlstrøm, S., \& Knutsen, S. H. (2006). Contents of starch and non-starch polysaccharides in barley varieties of different origin. Food Chemistry, 94(3), 348-358. http://dx.doi.org/10.1016/j.foodchem.2004.11.022.

Hu, C., Zawistowski, J., Ling, W., \& Kitts, D. D. (2003). Black rice (Oryza sativa L. indica) pigmented fraction suppresses both reactive oxygen species and nitric oxide in chemical and biological model systems. Journal of Agricultural and Food Chemistry, 51(18), 5271-5277. http://dx.doi.org/10.1021/jf034466n. PMid:12926869.

Iqbal, S., Bhanger, M. I., \& Anwar, F. (2005). Antioxidant properties and components of some commercially available varieties of rice bran in Pakistan. Food Chemistry, 93(2), 265-272. http://dx.doi. org/10.1016/j.foodchem.2004.09.024.

Jun, H.-I., Song, G. S., Yang, E. I., Youn, Y., \& Kim, Y. S. (2012). Antioxidant activities and phenolic compounds of pigmented rice bran extracts. Journal of Food Science, 77(7), C759-C764. http:// dx.doi.org/10.1111/j.1750-3841.2012.02763.x. PMid:22708681.

Kusirisin, W., Jaikang, C., Chaiyasut, C., \& Narongchai, P. (2009). Effect of polyphenolic compounds from Solanum torvum on plasma lipid peroxidation, superoxide anion and cytochrome P450 2E1 in human liver microsomes. Medicinal Chemistry, 5(6), 583-588. http://dx.doi. org/10.2174/157340609790170443. PMid:20041835.

Laokuldilok, T., Shoemaker, C. F., Jongkaewwattana, S., \& Tulyathan, V. (2011). Antioxidants and antioxidant activity of several pigmented rice brans. Journal of Agricultural and Food Chemistry, 59(1), 193199. http://dx.doi.org/10.1021/jf103649q. PMid:21141962.

Lerma-García, M. J., Herrero-Martinez, J. M., Simo-Alfonso, E. F., Mendonca, C. R. B., \& Ramis-Ramos, G. (2009). Composition, 
industrial processing and applications of rice bran $\gamma$-oryzanol. Food Chemistry, 115(2), 389-404. http://dx.doi.org/10.1016/j. foodchem.2009.01.063.

Lin, P. Y., \& Lai, H. M. (2011). Bioactive compounds in rice during grain development. Food Chemistry, 127(1), 86-93. http://dx.doi. org/10.1016/j.foodchem.2010.12.092.

Muthayya, S., Sugimoto, J. D., Montgomery, S., \& Maberly, G. F. (2014). An overview of global rice production, supply, trade, and consumption. Annals of the New York Academy of Sciences, 1324(1), 7-14. http:// dx.doi.org/10.1111/nyas.12540. PMid:25224455.

Patel, M., \& Naik, S. N. (2004). Gamma-oryzanol from rice bran oil: a review. Journal of Scientific and Industrial Research, 63, 569-578.

Pengkumsri, N., Chaiyasut, C., Saenjum, C., Sirilun, S., Peerajan, S., Suwannalert, P., Sirisattha, S., Sivamaruthi, B. S. (2015). Physicochemical and antioxidative properties of black, brown and red rice varieties of northern Thailand. Food Science and Technology, httpI://dx.doi. org/10.1590/1678-457X.6573.

Rattanachitthawat, S., Suwannalert, P., Riengrojpitak, S., Chaiyasut, C., \& Pantuwatana, S. (2010). Phenolic content and antioxidant activities in red unpolished Thai rice prevents oxidative stress in rats. Journal of Medicinal Plants Research, 4(9), 796-801.

Salgado, J. M., Oliveira, A. G., Mansi, D. N., Donado-Pestana, C. M., Bastos, C. R., \& Marcondes, F. K. (2010). The role of black rice (Oryza sativa L.) in the control of hypercholesterolemia in rats. Journal of Medicinal Food, 13(6), 1355-1362. http://dx.doi.org/10.1089/ jmf.2009.0246. PMid:21091249.
Singh, V. K., Beattie, L. A., \& Seed, T. M. (2013). Vitamin E: tocopherols and tocotrienols as potential radiation countermeasures. Journal of Radiation Research, 54(6), 973-988. http://dx.doi.org/10.1093/jrr/ rrt048. PMid:23658414.

Suwannalert, P., Rattanachitthawat, S., Chaiyasut, C., \& Riengrojpitak, S. (2010). High levels of 25-hydroxyvitamin D3 [25(OH) D3] and a-tocopherol prevent oxidative stress in rats that consume Thai brown rice. Journal of Medicinal Plants Research, 4(2), 120-124.

Suzuki, M., Kimura, T., Yamagishi, K., Shinmoto, H., \& Yamaki, K. (2004). Comparison of mineral contents in 8 cultivars of pigmented brown rice. Journal of the Japanese Society for Food Science and Technology, 51(8), 424-427. http://dx.doi.org/10.3136/nskkk.51.424.

Wahid, H., Habib, K., \& Sadok, B. (2014). Physicochemical properties and antioxidant activity of Tunisian date palm (Phoenix dactylifera L.) oil as affected by different extraction methods. Food Science and Technology, 34(3), 464-470.

Yawadio, R., Tanimori, S., \& Morita, N. (2007). Identification of phenolic compounds isolated from pigmented rices and their aldose reductase inhibitory activities. Food Chemistry, 101(4), 1616-1625. http://dx.doi.org/10.1016/j.foodchem.2006.04.016.

Zhou, C., Tabb, M. M., Sadatrafiei, A., Grün, F., Sun, A., \& Blumberg, B. (2004). Hyperforin, the active component of St. John's wort, induces IL-8 expression in human intestinal epithelial cells via a MAPK-dependent, NF-kappaB-independent pathway. Journal of Clinical Immunology, 24(6), 623-636. http://dx.doi.org/10.1007/ s10875-004-6248-z. PMid:15622447. 